\title{
Evaluating the Effectiveness of Continuous Composite Beams for Steel-Concrete Bridges and Control Concrete Cracks of the Supports at an Early Age
}

\author{
Trong-Chuc Nguyen ${ }^{1,2, *}$, Trong-Phuoc Huynh ${ }^{3}$, Nguyen-Trong $\mathrm{Ho}^{4}$, Al-Amin Abdun Noor ${ }^{1}$ \\ ${ }^{1}$ Moscow State University of Civil Engineering, Yaroslavskoye Shosse, 26, Moscow, 129337, \\ Russia \\ ${ }^{2}$ Le Quy Don Technical University, No. 236, Hoang Quoc Viet St., Bac Tu Liem Dist., Ha Noi City, \\ Viet Nam \\ ${ }^{3}$ Can Tho University, Campus II, 3/2 St., Ninh Kieu Dist., Can Tho City 900000, Viet Nam \\ ${ }^{4}$ VŠB - Technical University of Ostrava Ludvíka Podéště 1875/17, 70833 Ostrava, Poruba Czech \\ Republic
}

\begin{abstract}
This study presents a solution to contextualized span bridges constructed with composite steel girders with reinforced concrete slabs by reinforced concrete. This kind of structure, in comparison with a simple span, has many advantages as overcoming internal forces, reducing large displacements and cutting the number of expansion joints. Also, numerical simulations were conducted to evaluate the effectiveness of continuous composite beams for steel-concrete bridges and control of cracking of concrete at the supports at an early age. The models and conclusions in this paper can provide safety guidance for construct composite steel girder bridge in Vietnam.
\end{abstract}

\section{Introduction}

Structure of composite steel girders with reinforced concrete slabs is a kind of structure, on which, when every member work together, they could promote the bearing capacity of materials: enormous compressive strength of concrete, the high tensile strength of steel and maintain economic efficiency in the same time [1-3]. Bridges with simple spans, in comparison with continuous spans, usually come up with higher internal forces, the more significant amount of materials and more inconvenient movement because of the existence of expansion joints. Using reinforced concrete to continual span bridges could fix this failure $[4,5]$.

Nowadays, some countries like Germany and France have been applying this contextualizing structure to many kinds of construction such as contextualizing slab desk, contextualizing main girders, contextualizing completely by using longitudinal pre-stressed reinforcement, contextualizing completely by using longitudinal reinforcement for joints (contextualizing slab linked by latch, horizontal continuous girder, horizontal cantilever

* Corresponding author: ntchuc.mta198@gmail.com 
beam, continuous bridge, contextualizing-heating desk), contextualizing by changing two rows of wedges on the top of supports into one, contextualizing by continuously casting concrete and change system of spans into system of bridge-frame [6].

In Germany, several bridges have been constructed by continuous pouring concrete at the supports and the abutments. The concrete at the supports and the abutments as concrete transverse girders. The typical bridge project as the bridge over the river Nahe near Niederhausen is a four-span composite bridge with spans of $25.87 \mathrm{~m}$, the bridge across the river Emscher in Oberhausen is a single span composite bridge with $40 \mathrm{~m}$ length for public traffic lanes, the composite bridge crossing the highway Berlin - Dresden near Schwarzheide is a 2-span bridge with spans of $31.14 \mathrm{~m}$ comprising 6 welded plate girders spaced $2.23 \mathrm{~m}$ and a precast partial depth slab... etc. [7]. The transverse beams at the abutments and the supported reinforced concrete sections after continuous composite beams by pouring concrete. At the early age day in concrete at the supports and the abutments occur thermal cracking of cement hydration [8-12].
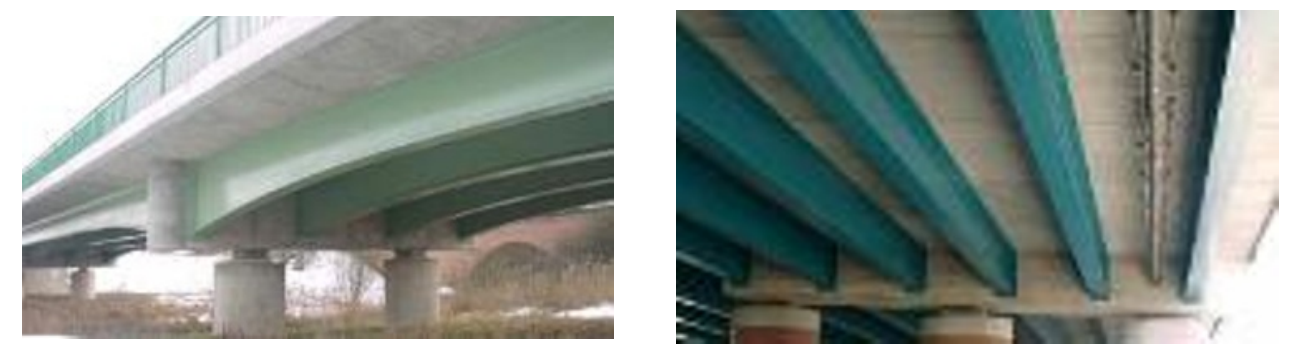

Fig. 1. The casting concrete to continual structures bridges across the river in Germany.

The present study aims to evaluate the effectiveness of continuous composite beams for steel-concrete bridges and control of cracking of concrete at the supports at an early age with building condition in Vietnam. Therefrom, were proposed to prevent cracking, it will have a significant reference on the large mass concrete structure in the future.

\section{Materials and methods}

\subsection{Materials of bridge beams}

The concrete bridge beams were used C50 concrete. To reduce the amount of cement hydration heat during the development intensity of concrete, pulverized fuel ash (PFA) was added to replace cement with a dosage of $15 \%$ is presented in Table 1 [13].

Table 1. Concrete mix proportion.

\begin{tabular}{|c|c|c|c|c|c|}
\hline \multicolumn{7}{|c|}{ Concrete mix proportion, $\mathbf{~ k g} / \mathbf{m}^{\mathbf{3}}$} \\
\hline Water & Cement & PFA & Fine aggregate & Coarse aggregate & Admixture \\
\hline 158 & 410 & 69 & 768 & 1045 & 5.6 \\
\hline
\end{tabular}

The properties of concrete used as input data during the analysis are presented in Table 2. Convection coefficient with the air of steel formwork is assessed to be $17.26 \mathrm{~W} /\left(\mathrm{m}^{2} \cdot{ }^{\circ} \mathrm{C}\right)$. During the construction of bridge girders, the ambient temperature varies from $15^{\circ} \mathrm{C}$ to $25^{\circ} \mathrm{C}$. Composite bridge cross section is presented in Table 3. 
Table 2. Properties of concrete.

\begin{tabular}{|l|c|c|}
\hline \multicolumn{1}{|c|}{ Properties of concrete } & Unit & Values \\
\hline Thermal conductivity coefficient & $\mathrm{W} / \mathrm{m} .{ }^{\circ} \mathrm{C}$ & 2.92 \\
\hline Specific heat capacity & $\mathrm{J} / \mathrm{kg} .{ }^{\circ} \mathrm{C}$ & 954 \\
\hline Density & $\mathrm{kg} / \mathrm{m}^{3}$ & 2450 \\
\hline Convection heat transfer coefficient & $\mathrm{W} / \mathrm{m}^{2} .{ }^{\circ} \mathrm{C}$ & 18.72 \\
\hline Coefficient of thermal expansion & $1 /{ }^{\circ} \mathrm{C}$ & $10^{-5}$ \\
\hline Modulus of elasticity of concrete & $\mathrm{GPa}$ & 34.50 \\
\hline Poisson's ratio & - & 0.20 \\
\hline Tensile strength at the age of 28 days & $\mathrm{MPa}$ & 4.10 \\
\hline The maximum heat release from cement hydration & $\mathrm{kJ} / \mathrm{kg}$ & 256 \\
\hline
\end{tabular}

Table 3. Basic dimensions of composite steel girders.

\begin{tabular}{|l|l|c|}
\hline \multicolumn{1}{|c|}{ Part } & Unit & Values \\
\hline The width of the top floor & $\mathrm{mm}$ & 350 \\
\hline The thickness of the top floor & $\mathrm{mm}$ & 20 \\
\hline The width of the bottom floor & $\mathrm{mm}$ & 400 \\
\hline The thickness of the bottom floor & $\mathrm{mm}$ & 22 \\
\hline The thickness of the web plate of the girdle & $\mathrm{mm}$ & 16 \\
\hline The height of the web plate of the girder & $\mathrm{mm}$ & 1358 \\
\hline The thickness of the reinforced concrete slab & $\mathrm{mm}$ & 200 \\
\hline The width of the reinforced concrete slab & $\mathrm{mm}$ & 3000 \\
\hline
\end{tabular}

\subsection{Characteristics of structures}

The solution for structure: at two ends of girder set up an open section bQRT, on which set down reinforcement and cast concrete to the regular system of simple spans. For the reason that girders lying on wedges work under high shear forces and high negative moment, need to strengthen reinforcement not only at the gap between girders, but also steel net for the bottom and top layers in girders themselves. In practical application when building bridges, the top reinforcement layer and the bottom reinforcement layer are often used with D16 diameter and $10 \mathrm{~cm}$ steps. Figure 3 shows that the length of reinforcement by the formula:

$$
\mathrm{l}=\mathrm{b}_{\mathrm{QRT}}+\mathrm{L}+\mathrm{l}_{\mathrm{b}} \text { (usually use } \mathrm{l}=0.15 \mathrm{~L}_{\text {span }} \text { ) }[14] \text {. }
$$

where: bQRT - the distance between two ends of girders;

$\mathrm{L}$ - more or equal to $0.15 \mathrm{Lst}$;

Lst - longer length one of two spans abutting on considered support;

$\mathrm{l}_{\mathrm{b}}$ - the length of anchor reinforcement.

For the chart of the negative bending moment under the influence of temperature, active loads and displacement (deformation) of supports, to increase the tensile strength of bottom desks, need to add more links for steel plates or more reinforcements. Higher shear forces, bigger quantity and step of reinforcements applied. The detailed structure for position contextualizing span bridges are shown in Figures 2 and 3. 


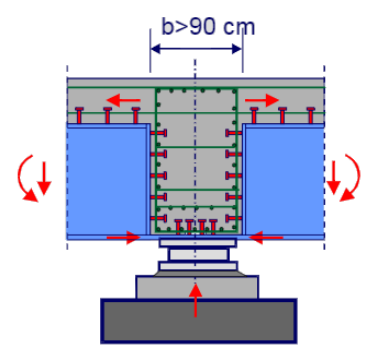

Fig. 2. Structure girders on supports [14].

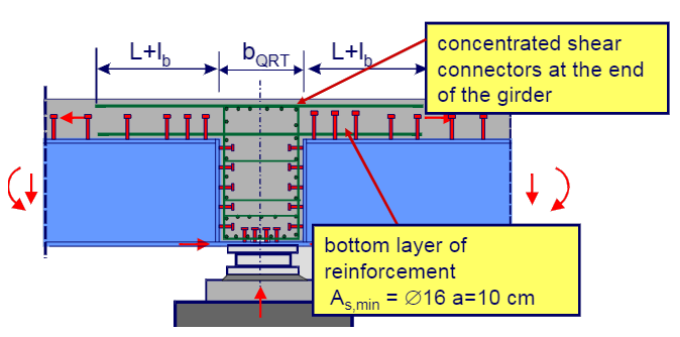

Fig. 3. The detailed structure for the position casting concrete to continual structures [14].

Anchor against cutting is the member's composite steel girders with reinforced concrete slabs. Need to set up quantity and step of reinforcements according to special calculations, at the position ending girders, and reinforced concrete slabs must have a thickness more or equal to $17.5 \mathrm{~cm}[15,16]$.

Working characteristics: contextualizing span bridges constructed with composite steel girder with reinforced concrete slab by reinforced concrete not only build continuous structures but also create an additional member the transverse beams at the abutments and the supported. The structure works in the following stages:

Stage 1: on which, only steel girders work, the geometric features of the cross-section are the geometric features of the steel girders.

Stage 2: on which, steel girders and reinforced concrete slabs work together.

Due to contextualizing span bridges by reinforced concrete at the position between two ending girders, notice that there are two different cross-sections in considered girder. Crosssections at the supports and the abutments are the geometric features of the cross-section are the geometric features of the steel girders. Cross-sections in the middle of spans are the geometric features of the cross-section are the geometric features of composite steel girders with a reinforced concrete slab [17, 18].

Do making other configuration about the physical beam between the cylinder and other cutting that the body value has a different distribution. The difference between materials composing girders and between cross-sections of girder lead to a different distribution of weight in girder itself is shown in Figure 4.

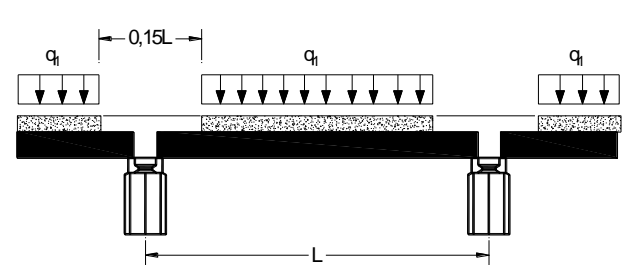

a) Casting of mid-span regions

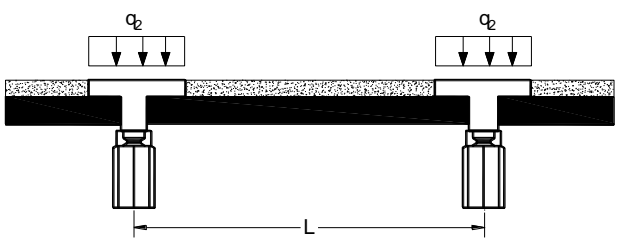

b) Casting of supporting beams and the slab at internal support

Fig. 4. Dead loads laying on girders.

Construction methods: depend on each length of span bridges, construction methods for desk bridges could be used, according to methods laying girders on supports. The following method is used:

- Step 1: forming steel girders, the system of linking anchors (for the top floor and the steel girders),

- Step 2: laying girders on supports (with the predefined step of spans),

- Step 3: laying reinforcement at the position between 2 ending girders and on desk bridges,

- Step 4: casting concrete for a desk in the middle of spans and the position of the wedge,

- Step 5: completing desk and auxiliary members. 


\subsection{The assessment of cracking in concrete at the abutments}

The assessment of cracking probability in the concrete due to the heat of hydration can be expressed by equation (1) [19-23].

$$
I_{c t}=\frac{f_{s p}(\tau)}{f_{t}(\tau)},
$$

where: Ict $_{\text {c }}$ thermal crack index;

$\mathrm{f}_{\mathrm{t}}(\tau)$ - the maximum thermal stress value at day $\tau$;

$f_{\text {sp }}(\tau)$ - the tensile strength of concrete at day $\tau$.

The cracking tendency can be assessed by the thermal crack index value based on previous testing and application experiences and prevented cracking criteria that are listed in Table 4.

Table 4. Criteria for controlling the cracking tendency of concrete.

\begin{tabular}{|l|c|}
\hline \multicolumn{1}{|c|}{ Criteria for evaluating crack } & Thermal cracking index $\left(\mathrm{I}_{\mathrm{cr}}\right)$ \\
\hline To prevent the formation of thermal cracks & $\mathrm{I}_{\mathrm{cr}} \geq 1.5$ \\
\hline To limit thermal cracks formation & $1.2 \leq \mathrm{I}_{\mathrm{cr}} \leq 1.5$ \\
\hline To limit the formation of harmful thermal cracks & $0.7 \leq \mathrm{I}_{\mathrm{cr}} \leq 1.2$ \\
\hline
\end{tabular}

\section{Results}

\subsection{Evaluate the effectiveness of continuous composite beams for steel-concrete bridges}

In this study, consider continuous girder with three spans, length of each span $\mathrm{L}=45 \mathrm{~m}$ under the effect of loads according to 22 TCN 272 - 05 is constructed in Vietnam conditions [24].

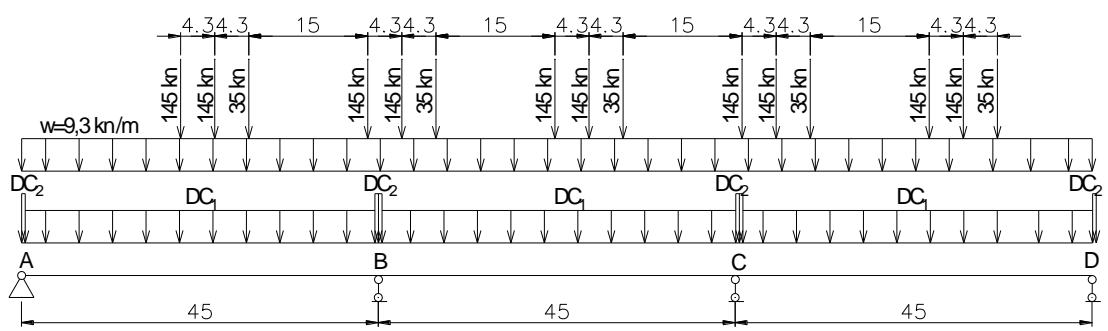

a)

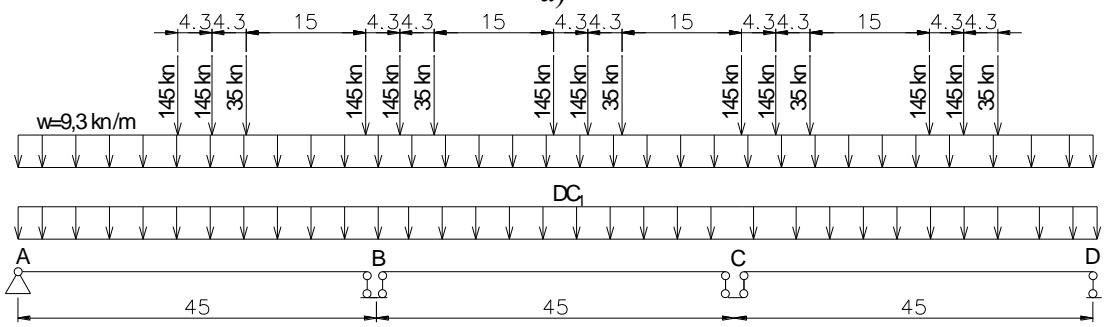

b)

Fig. 5. Structural analysis diagram for continuous span (a) and simple span (b). 
where: $\mathrm{DC}_{1}$ - the weight of the structure itself cross-section at the position composite steel girders with reinforces concrete slabs;

$\mathrm{DC}_{2}$ - the weight of the structure itself cross-section at the position laying wedges; w - lane load.

Gap between 2 ending girders (at supports), set bRT $_{\text {QRT }}=0.9 \mathrm{~m}$, the gap at wedge $\mathrm{b}=0.45$ $\mathrm{m}$ and one load combination include the weight of all components of the structure + HL-93 design truck + HL-93 design tandem and design lane load. Structural analysis diagram is shown in Figure 5. With the help of SAP 2000 software was determined internal forces (Moment) above 2 cases span continuous beams and girders simple are shown in Figures 610.

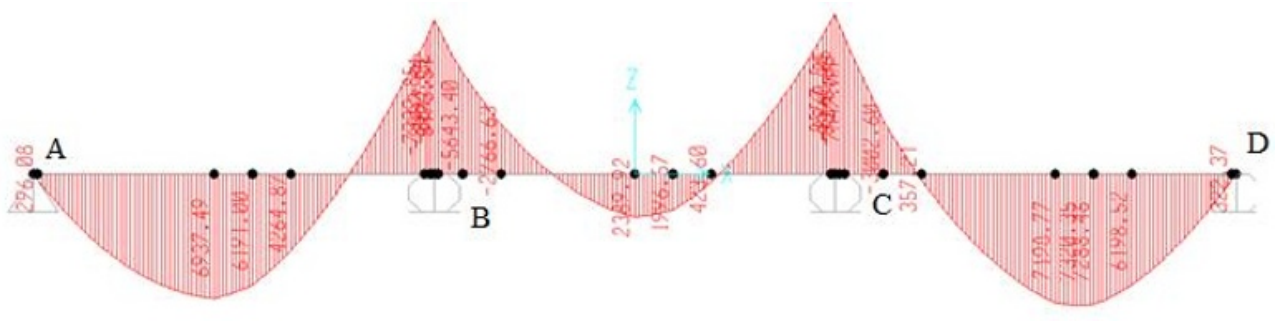

Fig. 6. Chart of the moment for continuous spans.

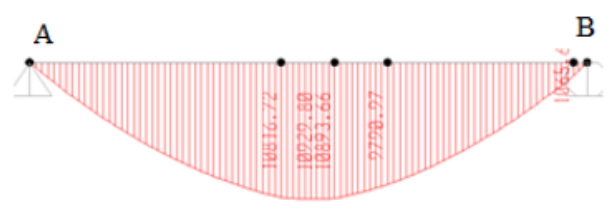

Fig. 7. Chart of the moment for simple span $\mathrm{AB}$.

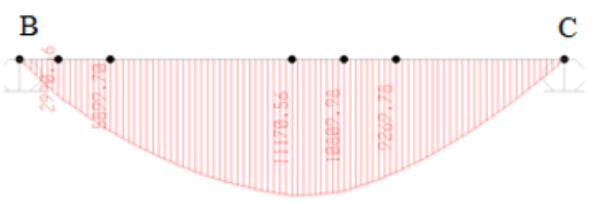

Fig. 8. Chart of the moment for simple span BC.

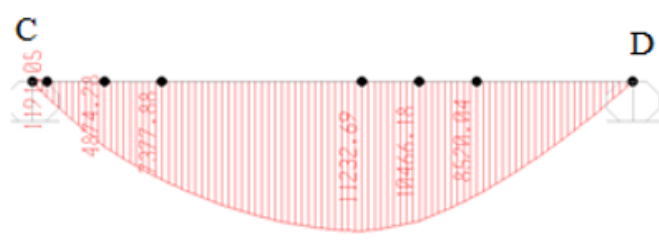

Fig. 9. Chart of the moment for simple span CD.

Figure 10 shows the bending moment value continuous span is less than the bending moment value simple span at the same load. For example, the bending moment at spans $\mathrm{AB}, \mathrm{BC}$, and $\mathrm{CD}$ of continuous span reduces $36.53 \%, 78.61 \%$, and $34.83 \%$ compared to bending moment at spans $\mathrm{AB}, \mathrm{BC}$, and $\mathrm{CD}$ of the simple span, respectively.

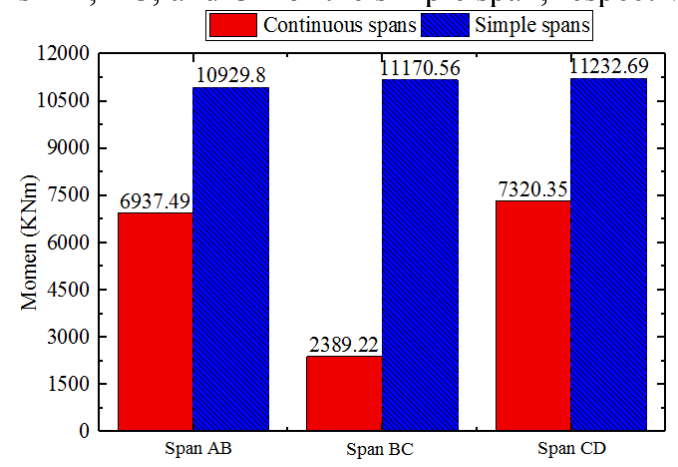

Fig. 10. Comparative values of moments on continuous spans with simple spans. 


\subsection{The assessment of cracking in concrete at an early age}

Consider the development of temperature, stress field and cracking index of concrete at the supports (which is responsible for continuous steel girder bridge) in concrete at an early age. The numerical model was used based on the finite element method to determine the temperature field and the cracking index of concrete at the supports using the commercial software Midas civil. Because of geometric symmetry, one part two of concrete at the supports was modeled by finite elements is shown in Figure 11.

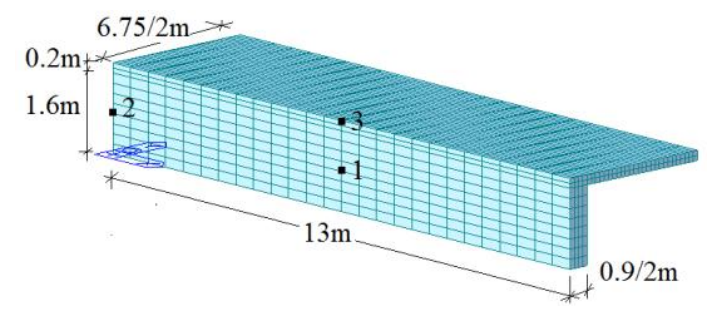

Fig. 11. Finite element model of one part two of concrete at the support.

When the temperature difference between the concrete at the support center and surfaces exceeds the allowable limit $20^{\circ} \mathrm{C}$, or the thermal crack index is less than the allowable $\mathrm{I}_{\mathrm{cr}}=1.5$. The result is the cracks appearing in the concrete center or surface. The analysis of the temperature field and the thermal crack index in three hazardous locations (the center - node 1 , structure outer left part - node 2 and the outer surface of structure upper part - node 3 ) is

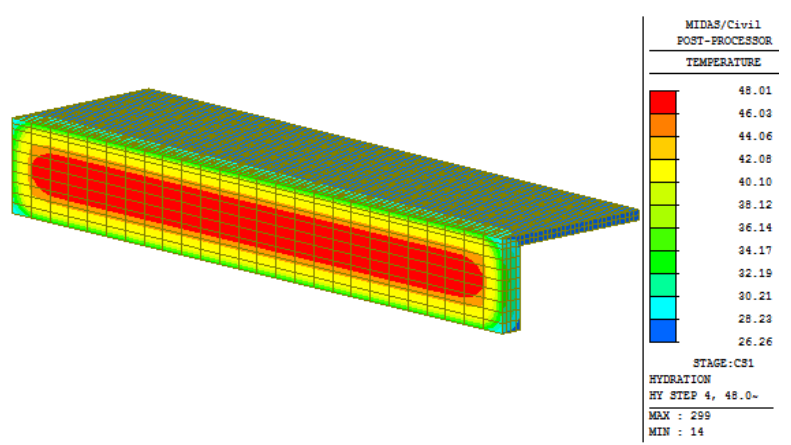

Fig. 12. The temperature distribution at the concrete at the support after 48 hours. shown in Figure 11.

Figure 12 shows the model predicted a maximum temperature of $48.01^{\circ} \mathrm{C}$ to occur at $48 \mathrm{~h}$. It can be seen from Figure 13 that the concrete at the support temperature difference between the center (node 1) and its surfaces (nodes 2 and 3 ) change over time.

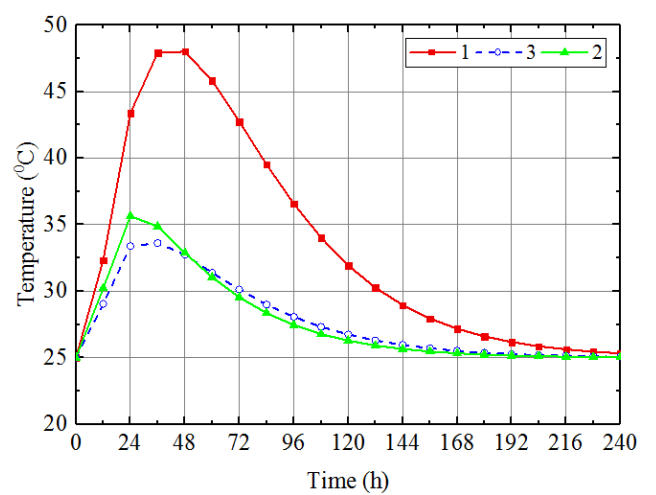

Fig. 13. Temperature curve at three points (node 1 - central; nodes 2,3 - surface) different of concrete at the support.

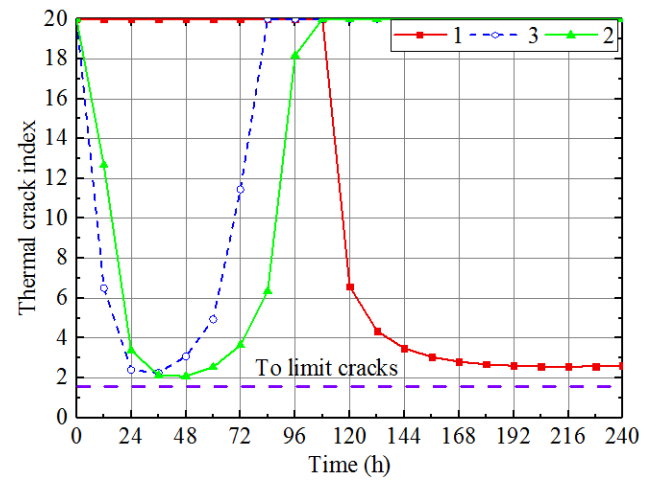

Fig. 14. The concrete cracking index at three points (node 1 - central; nodes 2, 3 - surface) change over time. 
Cracking indices for the concrete block predicted by the analysis are above the limit value of 1.5 at the 3 points of concrete at the support as seen in Figure 14. So it does not extend cracking of concrete at the support at early days.

\section{Conclusions}

Based on the results of the studies, the following conclusions:

1. Contextualizing span bridges constructed with composite steel girders with reinforced concrete slabs by reinforced concrete, in comparison with a simple span, has many advantages, e.g. cutting the number of expansion joints and creating a convenient movement for a vehicle on bridges. Under the effect of same loads, continuous spans also bring out the smaller value of internal forces (moment) than simple spans.

2. Contextualizing span bridges constructed with composite steel girders with reinforced concrete slabs by reinforced concrete could increase hardness for the whole structures.

3. Finite-element modeling can provide a more exact prediction of temperature field in concrete as well as give indications on cracking potential in concrete at the supports at an early age. There is no crack appear at the concrete of supports due to its cracking indices calculated larger than the limit value of 1.5.

This research was financially supported by the Moscow State University of Civil Engineering. Conflict of interest on behalf of all authors; the corresponding author states that there is no conflict of interest.

\section{References}

1. S. Chang-Su, L. Pil-Goo, C. Sung-Pil, J. of Construc. Steel Res. 57, 3 (2001)

2. L.Z. Deng and G. Michel, Eng. J. (New York) 37, 4 (2000)

3. N. X. Toan and N.V. My, Steel Bridge Design (Hanoi Construc. Pub., 2010)

4. Don W., Steel Bridge Design Handbook (Washington, 2015)

5. B. Bruno, Tobia Z., J. of Traff. and Trans. Eng. 2, 4 (2015)

6. P. Schaumann and J. Upmeyer, Composite bridges with precast concrete slabs (Univer.of Hanover Ins. for Steel Construc. 1998)

7. H. Kulka and P. Schaumann, S. und Tief. Magaz. 5 (1991) (in German)

8. N. Aniskin, N.T. Chuc and H.Q. Long, MATEC Web of Confer. 251 (2018) (https://doi.org/10.1051/matecconf/201825102014)

9. B. Klemczak, Knoppik-W. Agnieszka, Eng. Struc. 8 (2015)

10. K. Flaga, B. Klemczak, A. Knoppik-Wróbel, E. Conc. Fut.: Tech., Mod. \& Cons. 4 (2013)

11. V.T. Lam, T.N. Chuc, B. Bulgakov, N.P. Anh, MATEC Web of Confer. 196, 04017 (2018) (https://doi.org/10.1051/matecconf/201819604017)

12. V.T. Lam, T.N. Chuc, B. Bulgakov, N.P. Anh, Magaz. of Civ. Eng. 6 (2018) (https://doi.org/10.18720/MCE.82.13)

13. J. Du, X. Luo, and T.K.A. Francis, Adv. Mater. Res. 163-167 (2011)

14. I.G. Hanswille, Steel and composite bridges in Germany State of the Art (Ins. for Steel and Comp. Struc. Univer. of Wupp. Germany, 2016)

15. M.B. Daniel and E.R. George, Pract. Period. Struct. Des. Constr. 8, 2 (2003) 
16. E.R. George, R.W. Angela, L.W. Randall, Pract. Period. Struct. Des. Constr. 2, 3 (1997)

17. S. Martin, K. Thomas, Compo. Struc. 90 (2009)

18. Design Criteria for Bridges and Other Structures (Trans. and Main Roads, 2018)

19. N.T. Chuc, T.V. Lam, B.I. Bulgakov, Mater. Sci. For. 931 (2018) (https://doi.org/10.4028/www.scientific.net/MSF.931.667)

20. T.H. Hai, L.V. Thuc, J. of Sci. and Tech. in Ci. Eng. 11, 6 (2017)

21. N.T. Chuc, P.V. Thoan, B.A. Kiet, Electr. J. of Struc. Eng. 18, 2 (2018)

22. V.T Lam, T.N. Chuc, N.X. Hung, B.I. Bulgakov, S.I. Bazhenova and D.V. Phi, MATEC Web Conf. 193 (2018) (https://doi.org/10.1051/matecconf/201819303024)

23. K. Seo, H. Kim, C. Jin, J. of the Korea Ins. for struc. Mainten. and Inspec.11, 1 (2007)

24. 22TCN 272-05 2005. Bridge design standards (Ministry of Transport of Vietnam, 2005) 